\title{
Effects of a Proactive Interdisciplinary Self- Management (PRISMA) program on medication adherence in patients with type 2 diabetes in primary care: a randomized controlled trial
}

This article was published in the following Dove Medical Press journal:

Patient Preference and Adherence

Esther du Pon ${ }^{1,2}$

Siham El Azzati'

Ad van Dooren'

Nanne Kleefstra ${ }^{3,4}$

Eibert Heerdink $k^{1,5}$

Sandra van Dulmen ${ }^{6-8}$

'Research Group Process Innovations in Pharmaceutical Care, Utrecht University of Applied Sciences, Utrecht, the Netherlands; ${ }^{2}$ Diabetes

Centre, Isala Clinics, Zwolle, the Netherlands; ${ }^{3}$ Department of Internal Medicine, University Medical Center Groningen, University of Groningen, Groningen, the Netherlands; ${ }^{4}$ Medical Research Group, Langerhans, Ommen, the Netherlands; ${ }^{5}$ Department of Pharmaceutical Sciences, Utrecht University, Utrecht, the Netherlands; ${ }^{6}$ NIVEL (Netherlands Institute for Health Services Research), Department of Communication in Healthcare, Utrecht, the Netherlands; ${ }^{7}$ Radboud University Medical Center, Radboud Institute for Health Sciences, Department of Primary and Community care, Nijmegen, the Netherlands; ${ }^{8}$ Faculty of Health and Social Sciences, University of Southeast Norway, Drammen, Norway

Correspondence: Esther du Pon Research Group Process Innovations in Pharmaceutical Care, Utrecht University of Applied Sciences, PO Box I20II 350I AA Utrecht, the Netherlands

Tel +3I 6I 2923907

Email esther.dupon@hu.nl
Purpose: The present study aims to investigate the effect of the group-based Proactive Interdisciplinary Self-Management (PRISMA) training program on medication adherence in patients with type 2 diabetes (T2DM) treated in primary care.

Patients and methods: The current study is a two-arm, parallel group, randomized, open label trial (1:1) of 6-month duration with a 6-month extension period in which both groups received the intervention (wait-list control). People 18 years old or older who were diagnosed with T2DM were included. The intervention consisted of two group meetings about T2DM guided by care providers. The control group received usual care only (visits at the general practice). The primary outcome was adherence based on pharmacy refill data and was measured using medication possession ratio (MPR). The secondary outcomes were the number of drug holidays and self-reported adherence, measured by the 5-item Medication Adherence Rating Scale (MARS-5).

Results: Of the total sample ( $\mathrm{n}=108), 66.6 \%$ were male. The mean age was 69.3 years $(\mathrm{SD}=9.1)$. In the 6-month period, patients were more adherent in the intervention group $(n=56)$ (median MPR $=100.0$ [51.1-100.0]) than in the control group $(n=52)($ median MPR =97.7 [54.1-100.0]) ( $U=1,042, z=-2.783, P=0.005)$. The intervention group had less drug holidays than the control group (relative risk $0.55,95 \%$ CI, 0.37-0.80). The sum scores of the MARS did not differ between the intervention group ( median $=23.98, \mathrm{SD}=0.91$ ) and the control group (median $=24.00, \mathrm{SD}=1.54$ ). Conclusion: The PRISMA program resulted in a small improvement in MPR and fewer drug holidays, while no improvement has been found in self-reported adherence. However, health care providers and policy makers could take into account that adherence might be influenced by PRISMA.

Keywords: MPR, refill data, drug holidays, MARS, group education

\section{Introduction}

Type 2 diabetes mellitus (T2DM) is a highly prevalent, predominantly lifestyle-related, chronic condition. ${ }^{1}$ In the Netherlands, 51 per 1,000 persons are affected by T2DM. This rate is expected to increase to 80 per 1,000 persons in $2025,{ }^{2}$ especially - but not exclusively - among those with unhealthy lifestyles. ${ }^{3}$ T2DM is related to an increased risk of developing macro- and microvascular complications, including cardiovascular disease, diabetic retinopathy, neuropathy, and nephropathy. ${ }^{1}$

In the Netherlands, T2DM is mainly treated in primary care by the general practitioners (GPs) and the primary care practice nurse (PN). For patients with T2DM, 
restoring a healthy lifestyle is the cornerstone of treatment. Self-management is challenging, because the combination of adequate knowledge, skills, perseverance, and motivation to initiate and maintain behaviors that can help manage the disease on a daily basis is difficult for many patients to achieve. ${ }^{4}$ Influential self-management behaviors involve a healthier diet, more physical activity, self-monitoring of blood glucose levels when needed, and taking medication according to prescription. ${ }^{5}$

Most patients with T2DM additionally need to be treated with glucose-lowering medication (oral blood glucose-lowering medication, eventually followed by insulin). In 2014, in the Netherlands, 800,000 patients were treated with glucoselowering medication, and $82 \%$ of T2DM patients took their medication as prescribed. ${ }^{6}$ Medication adherence has been defined by the World Health Organization as the extent to which a person's medication taking behavior corresponds with agreed recommendations from a health care provider (HCP). ${ }^{7}$ Although medication adherence is a crucial factor in the effectiveness of a therapy, it is a complex behavior with several aspects, ${ }^{8}$ which makes it difficult to measure. ${ }^{9}$ Medication adherence can be divided into three interrelated yet distinct phases: the initiation of the treatment, the implementation of the prescribed regime, and the discontinuation of the pharmacotherapy. Medication non-adherence can occur in any of these phases. ${ }^{10}$ Non-adherence can be considered as a significant health care problem, especially for patients with chronic illnesses. ${ }^{11}$ In T2DM, glycemic (the levels of blood glucose) control is essential to prevent long-term macro- and microvascular complications.

One way to encourage self-management and lifestyle change is through group-based diabetes self-management education. ${ }^{12,13}$ Group-based education possesses the advantages of having patient meetings, discussions, and peer motivation. ${ }^{12}$ Furthermore, group-based education has been found to result in improvements in clinical, lifestyle, and psychosocial outcomes. ${ }^{14}$ In the Netherlands, the group-based Proactive Interdisciplinary Self-Management (PRISMA) training program was developed. It was adapted from the Diabetes Education and Self-Management for Ongoing and Newly Diagnosed (DESMOND) program developed in the UK for primary diabetes care. ${ }^{15-17}$ DESMOND was translated into Dutch and adapted to the Dutch health care system. With PRISMA, patients are challenged to consider their own personal risk factors and to choose a specific goal of behavior change. ${ }^{18}$ In the PRISMA sessions, the risk factors for T2DM were discussed, as well as the expected effect of insulin or oral blood glucose-lowering medication on blood glucose levels. In addition, patients were challenged to formulate their own personal risk factors and to choose a specific goal of behavior change, for example, "taking medication as prescribed." A better understanding of the ways that "medications" can affect T2DM could stimulate patients to be adherent to their medication therapy.

Moreover, because adherence is an important aspect of self-management, a change in medication intake due to PRISMA can be hypothesized. Unfortunately, little is known about the actual effect of these kinds of self-management education programs on medication adherence in patients with T2DM. ${ }^{19}$ The present study aims to investigate the effect of PRISMA on medication adherence in patients with T2DM treated in primary care.

\section{Patients and methods}

\section{Trial design}

The current study is part of the Diabetes Education and SelfManagement to Increase Empowerment (DESTINE) study, described in detail elsewhere. ${ }^{20}$

The current study was performed with data available from DESTINE. ${ }^{20}$ A power calculation was carried out on the primary outcome measure (platform use), and therefore a sample size calculation was not performed for examining effects on adherence in the present study.

DESTINE is a two-arm, parallel group, randomized, open label trial $(1: 1)$ conducted over a period of 6 months. The study investigated sustainability in the intervention group during a 6-month extension period (wait-list control), in which both groups received the intervention. The control group received the intervention as well because of ethical reasons. All patients were given the opportunity to attend the PRISMA program since positive effects were expected. An observational study had already shown some improvements of PRISMA in self-management behavior (dietary behaviors, foot care, and action planning). ${ }^{21}$

The patients $(n=203)$ with T2DM received either PRISMA in addition to usual care or usual care only. The GP saw patients once a year to manage their diabetes. In addition to these GP visits, every 3-6 months, the PN checked the patients' body weight, blood pressure, and (fasting) blood glucose levels. The PNs also inquired about their patients' well-being, hypo- or hyperglycemia, nutrition, exercise, and medication, when indicated.

This study was reviewed by the Medical Ethics Committee of Isala, Zwolle, the Netherlands, which decided that according to the Dutch law formal approval was not necessary (METC no 14.07104). The study was conducted in accordance with the Declaration of Helsinki, and registered at the Dutch Trial Register (no NTR4693). All participants 
gave written informed consent. All criteria of the CONSORT checklist and the minimum criteria of the EMERGE checklist were reported. Both checklists are available as supporting information (see Checklist S1 and Checklist S2). ${ }^{22,23}$

\section{Participants}

In DESTINE, people 18 years old or older who were diagnosed with T2DM and treated in primary care were included. The following exclusion criteria were applied by the participating GPs: 1) insufficient knowledge of the Dutch language to understand the requirements of the study and/or the questions posed in the questionnaires, 2) mental retardation, psychiatric treatment or schizophrenia, 3) mental disorder bipolar disorder, 4) life expectancy less than one year due to malignancies, 5) and any other serious condition that according to the GPs may interfere with trial participation or evaluation results. ${ }^{20}$

\section{Recruitment}

GPs $(n=8)$ in the eastern part of the Netherlands participated in the study. The GPs selected all eligible patients (see the section "Participants"). Eligible patients were then informed in detail and recruited by the primary investigator (EdP). There was no blinding for the participants, the investigator, or the HCP.

\section{Intervention}

The PRISMA program was offered in addition to usual care. The philosophy of PRISMA is based on patient empowerment, grounded in the following four psychological models: the self-regulation theory, ${ }^{24}$ the dual process theory, ${ }^{25}$ the self-determination theory, ${ }^{26}$ and the social learning theory. ${ }^{27}$ Although PRISMA was not specifically developed with the purpose to increase adherence, it may be improved because it is an important aspect of self-management. PRISMA aims to empower patients by using a non-didactic learning approach. Patients were stimulated to consider their own personal risk factors and to choose a specific goal of behavior change, for example, "taking a walk every morning," “quitting smoking," or "taking medication as prescribed."

The PRISMA program consisted of two meetings of 3.5 hours each. Groups were guided by a dietician and a PN, both experienced in diabetes care. These trainers had followed a standardized training program to ensure the quality of information delivery.

The first session of the PRISMA program concerned the following topics: ${ }^{17}$ patients' individual stories, T2DM, the effect of insulin or oral blood glucose-lowering medication on blood glucose levels, hyper- or hypoglycemia, monitoring of blood glucose levels, nutrition (carbohydrates and body weight), and in which stage of change the patients consider themselves with respect to their nutrition and physical activity. The second session concerned a retrospective of the first session, complications and personal risk factors, nutrition (fat), physical activity, and the patients' individual diabetes action plans.

The participants were stimulated to continue discussing their goals and actions with their HCP after completing the course. In the intervention group, the participants started receiving PRISMA along with usual care (Figure 1). The control group participants continued to receive usual care and were offered PRISMA after 6 months. Twenty PRISMA trainings (which consisted of two meetings each) were conducted to train all the included participants.

\section{Randomization}

To allocate participants to one of the two groups, nonstratified block randomization was used. The researcher performed the randomization over all general practices in a central place were patients' applications were collected. The participants were randomized in ten blocks of 20 participants each (ten per arm). The blocks were generated by the order of participants' entry, and each time 20 participants applied, who were randomized into two groups. After application, patients were matched to a research number which was written on a list in order of participants' entry. The list was used to make blocks of 20 participants. Finally, the researcher allocated closed, transparent envelopes with a note of the patients' research numbers to one of the groups.

\section{Outcomes}

In this analysis, two sources were used to measure adherence: 1) pharmacy refill data, and 2) self-reported data. The primary outcome was adherence based on pharmacy refill data and measured using the medication possession ratio (MPR). ${ }^{28}$ The secondary outcomes were the number of times when there was a gap of more than 3 days between the theoretical end date of the administration period and the dispensing date of the next prescription ("drug holidays"), also based on pharmacy refill data and self-reported adherence, measured by the 5-item Medication Adherence Rating Scale (MARS-5). ${ }^{29}$ This study focused on the adherence phase, that is, "suboptimal implementation of the dosing regimen," for example, late, skipped, extra, or reduced doses or drug holidays.

\section{Pharmacy data: MPR}

Access to information about the number of dosages dispensed and the dispensing dates was provided by the eleven pharmacies where the participants were registered. In the 


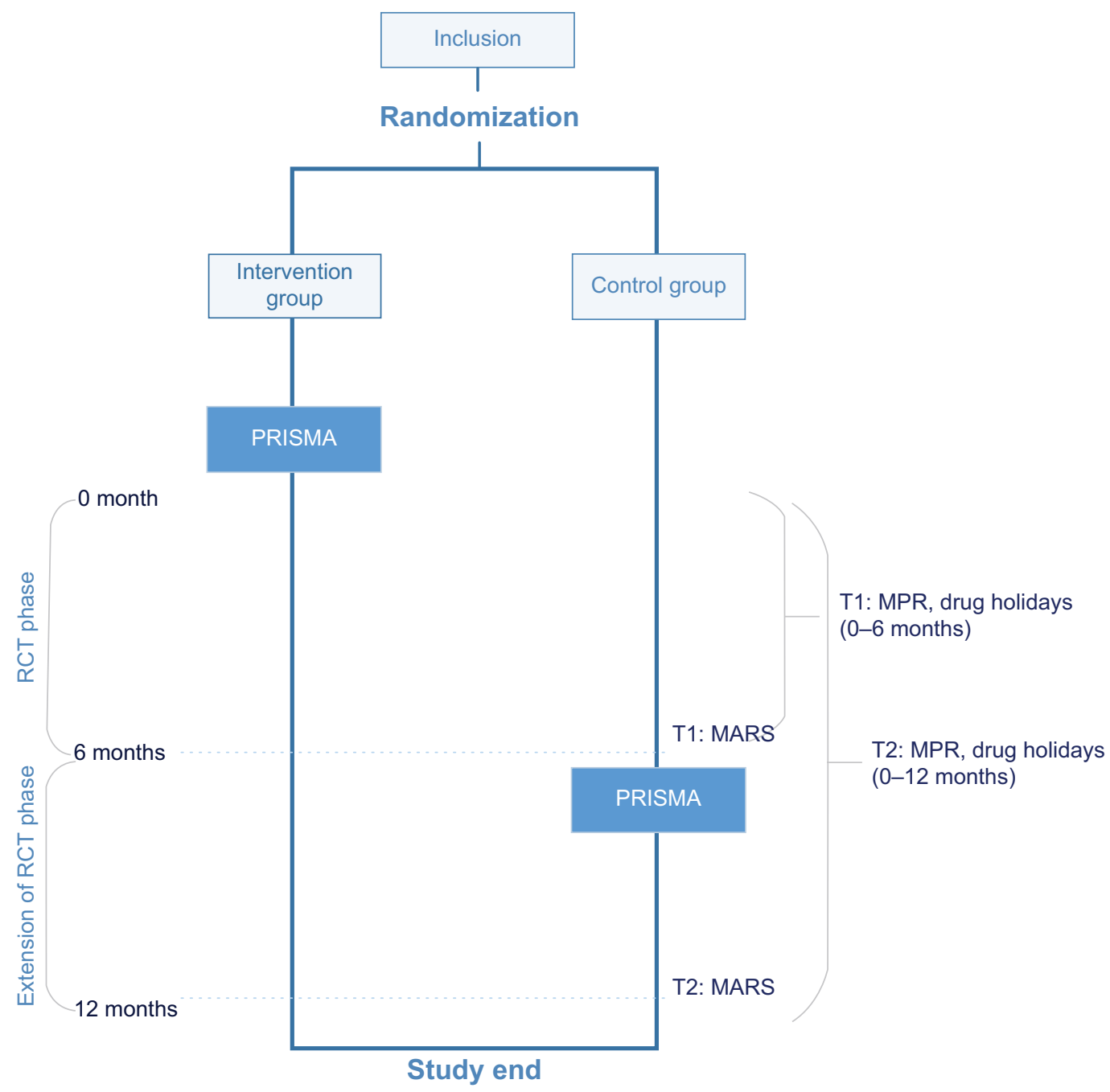

Figure I Trial design.

Note: The control group also received PRISMA after 6 months (wait-list control).

Abbreviations: PRISMA, Proactive Interdisciplinary Self-Management; RCT, randomized controlled trial; MPR, medication possession ratio; MARS, Medication Adherence Rating Scale.

Netherlands, virtually all patients pick up their medication at a single pharmacy. ${ }^{30}$ The medication status and medication history of each patient were extracted from the pharmacies' computer information systems.

Adherence to medication was determined using the MPR. ${ }^{9}$ The following three phases describe the process for calculating an adherence percentage.

\section{Phase I: calculate a measuring period}

The measuring period started with the first prescription of medication before the start of the intervention, or with the first medication after the start of the intervention in the case of new users. The measuring period ended with the first medication prescription 6 months (182 days) after the start of the intervention, or - in the case where no medication was used after 182 days - with the last available medication prescription.

\section{Phase 2: calculate the MPR}

In the measuring period, the number of days for which the medication was dispensed was divided by the number of days from the first prescription during that period until the end of the measurement period. The outcome was expressed as a percentage which ranges from $0 \%$ to $100 \%$. The higher the MPR, the more adherent the patient is.

\section{Phase 3: determine how to handle exceptions}

For patients who used more than one medication for their T2DM, the adherence for every specific medication was measured separately. If patients used two or three medications simultaneously, the medication with the lowest adherence percentage was analyzed, because the study focused on investigating non-adherence. When patients picked up their medication too early, multiple prescriptions could 
have overlapped. Such overlaps were corrected by the next prescription as follows: the overlap of two prescriptions was corrected by adding the number of days of overlap in the first prescription date and the theoretical end date of the second prescription.

\section{Drug holidays and self-reported adherence}

Dose omissions represented a common form of nonadherence in patients with T2DM. Therefore, drug holidays were a valuable and clinically relevant outcome. ${ }^{31}$ As mentioned earlier, by using the MPR over a period of time, gaps could be corrected by overlaps later. However, by adding drug holidays as an outcome, it could be detected when patients had no medication in stock. The number of drug holidays was determined by counting the number of times there was a gap of more than 3 days between the theoretical end date of the administration period and the dispensing date of the next prescription. Whether patients had one or more drug holidays (yes/no) was reported, as well as categorized into the following: no drug holiday, one drug holiday, and two or more drug holidays. To assess self-reported adherence to medication prescriptions, participants were asked to complete the MARS-5 questionnaire. This was done at the baseline (ie, directly after the PRISMA training), and after 6 months and 12 months. The MARS- 5 consisted of five general statements about non-adherent behavior ("I forget to take my medicines; I alter the dose of my medicines; I stop taking my medicines for a while; I decide to miss a dose; and I take less than instructed") answered on a 5-point Likert scale ( $1=$ always, $2=$ often, $3=$ sometimes, $4=$ rarely, and $5=$ never $)$. The total MARS-5 score was calculated by summing scores from each individual question (range $=5-25$ ). Higher scores indicate lower self-reported adherence. The level of education was also obtained from these questionnaires. The MARS has been validated in Dutch. ${ }^{32}$

\section{Analysis}

Pharmacy refill data (MPR) and drug holiday data were available over a period of 6 and 12 months, and self-reported data (MARS) at two points of time: 6 and 12 months. The current study distinguished two phases: a randomized controlled trial (RCT) phase (0-6 months) and an extension of the RCT phase (0-12 months) (Figure 1).

At first, differences between the intervention group and the control group were investigated during the RCT phase over a period of 6 months, and subsequently, during the extension of the RCT phase over a period of 12 months.
For the RCT phase, an intention to treat (ITT) analysis and a per protocol (PP) analysis were conducted. The PP analysis included only patients of the intervention group who followed PRISMA.

For both the intervention group and the control group, the MPR was reported in two categories (yes/no), and the drug holidays were reported in two categories (yes/no) and in three categories (no drug holiday, one drug holiday, and more than one drug holiday). Also, the scores on the five items and the average score were calculated (MARS).

\section{Statistical methods}

Treatment comparisons for efficacy end points were assessed with two-sided tests at a significance level of 0.05 , including a 95\% CI. All efficacy analyses were done in the ITT population. The analyses in the extension phase comprised all patients of the ITT who were randomly assigned in the first phase and received PRISMA in the second phase (between 6 and 12 months). Quantitative variables are described as mean and standard deviation, and categorical variables are described in numbers and percentages. Independent samples $t$-tests were used to test differences between the groups in the case of normally distributed variables; otherwise, the Mann-Whitney test was used. The chi-squared tests were utilized for categorical data. When PP analyses are done, this is stated explicitly. Statistical analyses were conducted by using IBM SPSS statistics version 22 .

\section{Results}

The inclusion period lasted 9 months (June 2014 to February 2015). Of 1,476 patients, 203 (13.8\%) were included in the study and signed the informed consent form; 101 patients were randomized in the intervention group and 102 in the control group. Furthermore, ten patients (4.9\%) withdrew from the study: six in the intervention group and four in the control group. In addition, 31 patients (15.3\%) did not use blood glucose-lowering medication ( $n=15$ in the intervention group; $\mathrm{n}=16$ in the control group), and for 54 patients $(26.6 \%)$ sufficient pharmacy data were not available $(n=24$ in the intervention group; $n=30$ in the control group). Therefore, they had no adherence data available and could not be included in the analysis. In the intervention group, 46 (82\%) of 56 patients attended at least one of the two PRISMA meetings. The patient flow chart is presented in Figure 2.

\section{MPR and drug holidays}

In the 6-month period, for measuring the MPR and drug holidays, $108(53.2 \%)$ of the 203 included patients were 


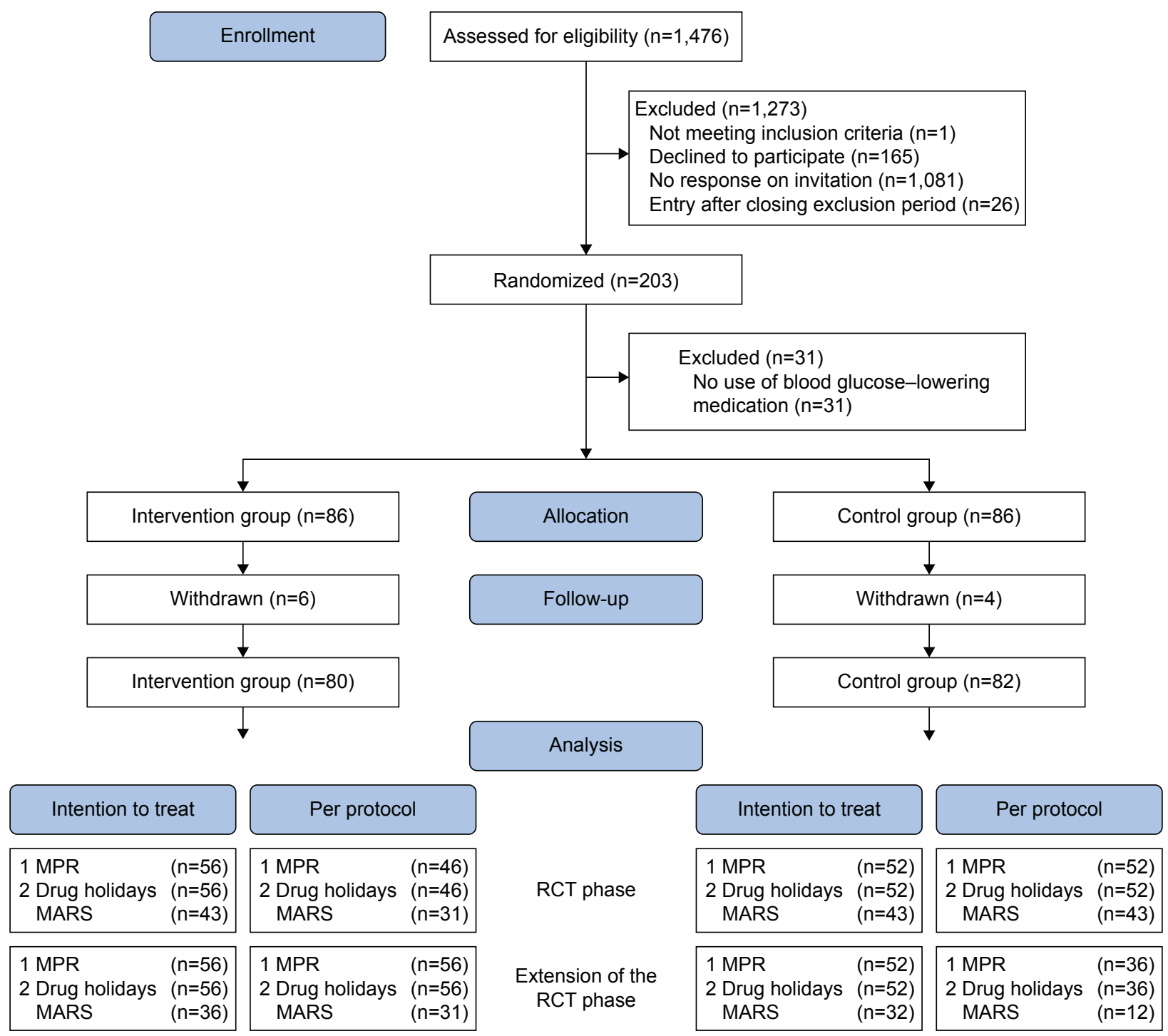

Figure 2 Patient flowchart.

Note: Patients from the larger trial who did not use blood glucose-lowering medication $(n=31)$ were excluded from this study.

Abbreviations: RCT, randomized controlled trial; MPR, medication possession ratio; MARS, Medication Adherence Rating Scale.

analyzed for ITT ( $n=56$ in the intervention group; $n=52$ in the control group). In the PP analysis, patients of the intervention group who did not attend PRISMA were excluded $(\mathrm{n}=10)$. Consequently, 98 (90.7\%) of the 108 patients were analyzed.

In the 12-month period, for measuring the MPR and drug holidays, for the PP analysis, patients $(\mathrm{n}=16)$ of the control group who did attend PRISMA between 6 and 12 months were also excluded. Consequently, $92(85.2 \%)$ of the 108 patients were analyzed.

\section{MARS}

The 6-month MARS questionnaire was completed by 86 (52.8\%) of the 163 patients ( $\mathrm{n}=43$ in the intervention group; $\mathrm{n}=43$ in the control group). These 86 patients were analyzed for ITT. In the PP analysis, patients ( $\mathrm{n}=12)$ of the intervention group who did not attend PRISMA were excluded. Consequently, 74 (86.0\%) of the 86 patients were analyzed.

The 12-month MARS questionnaire was completed by $68(41.7 \%)$ of the 163 patients. These 68 patients were analyzed for ITT. In the PP analysis, patients $(n=5)$ of the intervention group who did not attend PRISMA as well as patients $(n=20)$ of the control group who did attend PRISMA between 6 and 12 months were excluded. Consequently, 43 patients $(63.2 \%)$ were analyzed.

\section{Patient characteristics}

The patient characteristics are presented in Table 1. Of the total sample ( $\mathrm{n}=108), 66.6 \%$ were male. The mean age was 
Table I Patient characteristics $(n=108)$

\begin{tabular}{|c|c|c|}
\hline Characteristics & Intervention group $(n=56)$ & Control group $(n=52)$ \\
\hline Male (\%) & $38(66.7)$ & $34(64.2)$ \\
\hline \multicolumn{3}{|l|}{ Age in categories (years) } \\
\hline $50-59$ & $12(21.4)$ & $6(11.5)$ \\
\hline $60-69$ & $18(32.1)$ & $15(28.8)$ \\
\hline $70-79$ & $21(37.5)$ & $21(40.4)$ \\
\hline$\geq 80$ & $5(8.9)$ & $10(19.2)$ \\
\hline \multicolumn{3}{|l|}{ Education level (\%) ${ }^{\mathrm{a}}$} \\
\hline Low & $2(3.6)$ & $5(9.6)$ \\
\hline Moderate & $26(46.4)$ & $27(51.9)$ \\
\hline High & $11(19.6)$ & $6(11.5)$ \\
\hline Unknown & $17(30.4)$ & $14(26.9)$ \\
\hline Diabetes duration in years (median, IQR) & $6(4-9)$ & $7(4-9)$ \\
\hline Number of blood glucose-lowering medications (\%) & & $27(51.9)$ \\
\hline One & $36(64.3)$ & $24(46.2)$ \\
\hline Two & $18(32.1)$ & $\mathrm{I}(\mathrm{I} .9)$ \\
\hline Three & $2(3.6)$ & \\
\hline \multicolumn{3}{|l|}{ Type of blood glucose-lowering medication(s) (\%) } \\
\hline Metformin & $53(94.6)$ & $48(92.3)$ \\
\hline Gliclazide & $13(23.2)$ & $18(34.6)$ \\
\hline Tolbutamide & $9(16.1)$ & $9(I 7.3)$ \\
\hline Other & $4(7.2)$ & $2(3.8)$ \\
\hline Insulin & II (19.6) & $14(26.9)$ \\
\hline
\end{tabular}

Notes: ${ }^{\text {Low }}=$ no education or primary education; moderate = lower secondary education, (upper) secondary education, or post-secondary non-tertiary education (including vocational education); high = tertiary education (bachelor's degree or higher).

69.3 years $(\mathrm{SD}=9.1)$, with a minimum age of 50 years and a maximum of 87 years.

Table 2 presents the results of the MPR and the number of drug holidays for the period of 0-6 months and the scores on the items of the MARS at 6 months.

\section{MPR and drug holidays}

In the 6-month period, the median MPR was higher in the intervention group (100.0) compared to the control group (97.7) $(U=1,042, z=-2.783, P=0.005$ [Table 2]). Also, the intervention group was more often completely adherent compared to the control group; $\left(X^{2}(1)=8.21, P=0.004\right)$. In the 6-month period, the relative risk of having one or more drug holidays was lower for the intervention group compared to the control group (relative risk $0.55,95 \%$ CI, 0.37-0.80).

\section{MARS}

The sum scores of the MARS did not differ between the intervention group and the control group: $(\mathrm{M}=23.98, \mathrm{SD}=0.91)$ vs $(\mathrm{M}=24.00, \mathrm{SD}=1.54)$.

In the 12-month period, the MPR did not differ between the groups $(U=1,187.5, z=-1.752, P=0.080)$. Other results did not relevantly change in the 12-month period (data not shown).

The results of the PP analysis did not differ from the above-mentioned results (data not shown).

\section{Discussion}

First, PRISMA resulted in a significantly higher MPR in patients with T2DM over a 6-month period. Second, PRISMA also resulted in fewer drug holidays. On the other hand, self-reported adherence (MARS) did not differ between the groups. In the 12-month period, no differences between the groups were found in MPR and self-reported adherence.

These results show that PRISMA could be promising for improving adherence. Because PRISMA has not specifically been developed to improve adherence, the improvements could be related to the overall increase of self-management behaviors due to PRISMA. ${ }^{17,33}$ These improvements may also be attributed to the medication component discussed during PRISMA. PRISMA aims to empower patients. The enhanced knowledge about (advantages of taking) blood glucose-lowering medication could have stimulated patients to take their medication as agreed upon with their HCP. In addition, nonspecific effects may play a role, such as increasing patient attention by providing more contact hours with HCPs. The lacking effect of the MPR in the 12-month period could be explained by the fact that between 6 and 12 months both groups received the intervention. In addition, the MPR rates were already quite high. Although PRISMA resulted in fewer drug holidays, the number of drug holidays was already quite low (the ceiling effect). 
Table 2 Results of MPR, drug holidays, and MARS

\begin{tabular}{|c|c|c|}
\hline \multirow[t]{2}{*}{ Adherence outcomes } & \multicolumn{2}{|l|}{ 0-6 months } \\
\hline & Intervention group $(n=56)$ & Control group $(n=52)$ \\
\hline \multicolumn{3}{|l|}{ MPR } \\
\hline Median (IQR) & $100.0(98.0,100.0)^{\mathrm{a}}$ & $97.7(94.1,100.0)$ \\
\hline Range & $51.1-100.0$ & $54.1-100.0$ \\
\hline$<100(\mathrm{n}, \%)$ & $18(32.1)^{\mathrm{a}}$ & $31(59.6)$ \\
\hline $100(n, \%)$ & $38(67.9)$ & $21(40.4)$ \\
\hline \multicolumn{3}{|l|}{ Drug holidays } \\
\hline One or more drug holidays $(\mathrm{n}, \%)$ & $14(25.0)$ & $28(53.8)$ \\
\hline \multirow[t]{3}{*}{ Relative risk $(95 \% \mathrm{Cl})$} & $0.6(0.4-0.8)^{\mathrm{a}}$ & \\
\hline & \multicolumn{2}{|l|}{6 months } \\
\hline & Intervention group $(n=43)$ & Control group $(n=43)$ \\
\hline \multicolumn{3}{|l|}{ MARS (median [range]) } \\
\hline Item I: I forget to take medicines & $4(3-5)$ & $4(3-5)$ \\
\hline Item 2: I alter the dose of my medicines & $5(3-5)$ & $5(3-5)$ \\
\hline Item 3: I stop taking my medicines for a while & $5(4-5)$ & $5(4-5)$ \\
\hline Item 4: I decide to miss out a dose & $5(3-5)$ & $5(3-5)$ \\
\hline Item 5: I take less than instructed & $5(3-5)$ & $5(3-5)$ \\
\hline Sum score & $24.0(0.9)$ & $24.0(1.5)$ \\
\hline
\end{tabular}

Note: andicates significance.

Abbreviations: MPR, medication possession ratio; MARS, Medication Adherence Rating Scale.

These results are in line with previous reports of selfmanagement education programs, which have been shown to improve medication adherence in patients with T2DM..$^{12,13}$ Tan et al improved medication adherence and the correct timing of intake in patients with poorly managed T2DM through their structured educational face-to-face program. In addition, the pictorial image and teach-back educational strategies of Negrabdeh et al seemed to improve medication adherence among patients with T2DM and low health literacy. HCPs often rely on the written word to deal with the lack of time to teach patients about self-management. However, in the study of Negrabdeh et al, as well as in the PRISMA program, simple educational strategies were used, such as asking definite questions, avoiding medical jargon, encouraging patients to ask questions, and utilizing simple pictures with limited content.

Regarding the MARS, the ceiling effect could explain why no significant effects were found on the MARS score: Patients reported themselves to be very adherent. No patients reported stopping taking medicines for a while, and almost no patients took less than instructed. According to Van Vught et al, primary care patients with T2DM who participated in the PRISMA program showed indications of improvement in illness perceptions, dietary behaviors, foot care, and action planning 3 months after the training. ${ }^{34}$ In that study, no effects on medication adherence were found. However, adherence was measured by only one item of the Summary of Diabetes Self-Care Activities questionnaire, which is of limited reliability. Clearly, the overall increase of selfmanagement behaviors which the PRISMA program was aimed to achieve, combined by the better understanding of the ways that "medications" can affect T2DM, was not enough to increase the patients' self-reported adherence.

\section{Strengths and limitations}

A strength of this study is the multi-measure approach, which was used to measure different adherence aspects. There are numerous tools available for measuring adherence; $;^{34}$ nonetheless, currently none of them can be considered the gold standard. ${ }^{35,36}$ Collecting refill data is an objective and relatively easy process compared to other methods such as pill counts. A main advantage of refill data is that adherence rates can be estimated without the patient being aware of it, which increases the accuracy of the estimates by eliminating any Hawthorne effect. ${ }^{37}$ In addition, the validated MARS questionnaire that was used for self-reported adherence can be deployed in any clinical setting and is quick and simple because it contains only five questions. ${ }^{29}$

Some limitations need to be mentioned as well. This study focused on the non-adherence phase, that is, suboptimal 
implementation of the dosing regimen. Late or incomplete initiation or non-initiation was not applicable, because only patients who were already treated by medication for their T2DM were included. In addition, early discontinuation (non-persistence) could not be detected because the patients' reasons for discontinuation of the treatment were unknown. For example, if any drug discontinuation was advised by prescriber verbally, without record, this would be missed out.

Despite the strength of using two measures, none of them measures true medication intake. The results do not absolutely reflect actual patients' drug intake, because patients fill their prescriptions more readily than they take their medicine.$^{38}$ By using electronic medication packaging devices, for example, it would be possible to observe each single intake and subsequent deviation from the prescribed regimen. ${ }^{34}$ In addition, because the actual medication pickup dates were unavailable in the pharmacy's computer information system, the prescription dates were used, which could have caused overestimation of adherence. Also, the reliability of medication adherence questionnaires is limited. ${ }^{39}$ Several factors could have caused overestimation of the adherence rate. The patients in this study reported themselves to be very adherent. In general, non-adherent patients do not take part voluntarily in studies or do not show up at interventions (the healthy worker effect). Moreover, this study measured adherence through pharmacy refills, and the measuring period only concerns the implementation phase. Furthermore, although self-reporting questionnaires are generally considered as the most cost-effective and time-efficient way to assess medication adherence, they have also been reported to sometimes overestimate adherence. ${ }^{40}$ It should be acknowledged that many patients were lost and could not be followed up with for this study. Originally, the patient sample was selected from a study ${ }^{20}$ in which patient selection was based on general criteria (people of 18 years and older, diagnosed with T2DM) instead of their medication intake specifically. Taking blood glucose-lowering medication was set as inclusion criteria for the current study. The fact that patients who did not use these medications were excluded after randomization could have affected the results. The study investigated sustainability in the intervention group during the 6-month follow-up. This wait-list control design had the advantage of creating extra data, while a disadvantage was that no effects were expected. In addition, the MARS-5 questionnaire was completed by the participants after providing the PRISMA program instead of before. This could have been resulted in even more socially desirable answers on the MARS-5 questionnaire. Furthermore, despite our efforts to enthuse patients about the PRISMA program, only $12 \%$ of the approached patients participated. The year before the start of the study, the PRISMA program was already offered to patients treated by several GPs in the Zwolle region, which could be an explanation. Patients with an incomplete MARS questionnaire were excluded from the analysis because their total MARS score was not comparable with the rest of the study population. Hence, by excluding them, imputation became unnecessary. The large losses to follow-up and the low participation rate could have affected the generalizability of the study. A disadvantage of these kinds of trials is the healthy worker effect, which made the results less generalizable over all T2DM patients in the Netherlands.

\section{Conclusion}

Although PRISMA was not specifically developed to increase adherence in patients with T2DM, a small improvement has still been found in the MPR over a 6-month period. PRISMA also resulted in fewer drug holidays over a 6- and 12 -month period. No effects were found in self-reported adherence. The adherence rates were quite high already. Theoretically based group education such as PRISMA can influence health, psychological, and lifestyle outcomes. ${ }^{15,4}$ PRISMA was originally developed with the purpose to increase self-management behavior in patients with T2DM. However, HCPs and policy makers could take into account that adherence, as part of diabetes self-management, might be influenced by PRISMA. Nowadays, the most recent version of PRISMA is extended with education about adherence. For future research, it would be of interest to test whether this version has a stronger effect on adherence compared to the former one.

\section{Ethics approval and informed consent}

This study was reviewed by the Medical Ethics Committee of Isala, Zwolle, the Netherlands, which decided that formal approval was not necessary (METC no 14.07104). All participants gave written informed consent.

\section{Data availability (where applicable)}

The data sets generated and/or analyzed during the current study are not publicly available because public access was not included in the informed consent.

\section{Acknowledgments}

We thank all the pharmacists for their help during the extraction of the patient data from the pharmacies' computer 
information systems; Marcel Bouvy and Marcia Vervloet for their advice regarding the methods; and Laraib Pervez for her preliminary investigation regarding our research topic. This study was funded by the University of Applied Sciences Utrecht and the Dutch Foundation Care Within Reach (in Dutch: Stichting Zorg Binnen Bereik). These funding sources had no involvement in the study design; in the collection, analysis, and interpretation of data; in the writing of the report; and in the decision to submit the article for publication.

\section{Disclosure}

The authors report no conflicts of interest in this work.

\section{References}

1. World Health Organization. Global report on diabetes [online]; 2016. Available from: http://www.who.int/diabetes/global-report/en/. Accessed November 1, 2018.

2. Kleefstra N, Landman GW, van Hateren KJ, et al. Dutch diabetes prevalence estimates (DUDE-1). J Diabetes. 2016;8(6):863-865.

3. Bilo HJ, Houweling ST. [Increase in the number of people with diabetes mellitus [Toename van het aantal mensen met diabetes mellitus: noodzaak van een deltaplan]: need for a master plan]. Ned Tijdschr Geneeskd. 2009;153:A629. Dutch.

4. Thoolen B, de Ridder D, Bensing J, Gorter K, Rutten G. Beyond good intentions: the development and evaluation of a proactive selfmanagement course for patients recently diagnosed with type 2 diabetes. Health Educ Res. 2008;23(1):53-61.

5. Funnell MM, Brown TL, Childs BP, et al. National standards for diabetes self-management education. Diabetes Care. 2012;35(Supplement_1): S101-S108.

6. Kengetallen SF. Criteria berekening therapietrouw bij orale diabetica scherper geformuleerd, therapietrouw bij diabetes $82 \%$ [Criteria adherence calculation more accurate, adherence in diabetes $82 \%$ ]. Pharm Weekbl. 2014;149:46. Dutch.

7. Sabaté E. Adherence to Long-Term Therapies: Evidence for Action. Geneva, Switzerland: World Health Organization; 2003.

8. Dimatteo MR. Variations in patients' adherence to medical recommendations: a quantitative review of 50 years of research. Med Care. 2004;42(3):200-209.

9. Arnet I, Kooij MJ, Messerli M, Hersberger KE, Heerdink ER, Bouvy M. Proposal of standardization to assess adherence with medication records: methodology matters. Ann Pharmacother. 2016;50(5):360-368.

10. Vrijens B, de Geest S, Hughes DA, et al. A new taxonomy for describing and defining adherence to medications. Br J Clin Pharmacol. 2012;73(5):691-705.

11. van den Brink-Muinen A, van Dulmen A, Schellevis FG, Bensing JM. Tweede Nationale Studie naar ziekten en verrichtingen in de huisartspraktijk [Second national study for diseases and actions in the general practice]. Oog voor communicatie: huisarts-patiënt communicatie in Nederland. Utrecht, the Netherlands: Nivel; 2004. Dutch.

12. Negarandeh R, Mahmoodi H, Noktehdan H, Heshmat R, Shakibazadeh E. Teach back and pictorial image educational strategies on knowledge about diabetes and medication/dietary adherence among low health literate patients with type 2 diabetes. Prim Care Diabetes. 2013;7(2):111-118.

13. Tan M, Magarey J, Chee S, Lee L, Tan M. A brief structured education programme enhances self-care practices and improves glycaemic control in Malaysians with poorly controlled diabetes. Health Educ Res. 2011;26(5):896-907.
14. Steinsbekk A, Rygg Lisbeth Ø, Lisulo M, Rise MB, Fretheim A. Group based diabetes self-management education compared to routine treatment for people with type 2 diabetes mellitus. A systematic review with meta-analysis. BMC Health Serv Res. 2012;12(1):213.

15. Davies MJ, Heller S, Skinner TC, et al. Effectiveness of the diabetes education and self management for ongoing and newly diagnosed (DESMOND) programme for people with newly diagnosed type 2 diabetes: cluster randomised controlled trial. BMJ. 2008;336(7642):491-495.

16. Gillett M, Dallosso HM, Dixon S, et al. Delivering the diabetes education and self management for ongoing and newly diagnosed (DESMOND) programme for people with newly diagnosed type 2 diabetes: cost effectiveness analysis. BMJ. 2010;341(1):c4093.

17. Leibbrandt AJ, Kiefte-de Jong JC, Hogenelst MHE, Snoek FJ, Weijs PJM. Effects of the PRO-active interdisciplinary self-management (PRISMA, Dutch DESMOND) program on dietary intake in type 2 diabetes outpatients: a pilot study. Clin Nutr. 2010;29(2):199-205.

18. Skinner TC, Carey ME, Cradock S, et al. "Educator talk" and patient change: some insights from the DESMOND (Diabetes Education and Self Management for Ongoing and Newly Diagnosed) randomized controlled trial. Diabet Med. 2008;25(9):1117-1120.

19. Minet L, Møller S, Vach W, Wagner L, Henriksen JE. Mediating the effect of self-care management intervention in type 2 diabetes: a meta-analysis of 47 randomised controlled trials. Patient Educ Couns. 2010;80(1):29-41.

20. du Pon E, Kleefstra N, van Dooren AA, et al. DESTINE: a PracticeBased Intervention to Increase Empowerment in Patients with Type 2 Diabetes - a Study Protocol of a Randomized Controlled Trial. Diabetes Manag. 2017;7(4):330-336.

21. van Vugt M, de Wit M, Bader S, Snoek FJ. Does low well-being modify the effects of PRISMA (Dutch DESMOND), a structured selfmanagement-education program for people with type 2 diabetes? Prim Care Diabetes. 2016;10(2):103-110.

22. Schulz KF, Altman DG, Moher D. Consort 2010 statement: updated guidelines for reporting parallel group randomized trials. Ann Intern Med. 2010;152(11):726-732.

23. de Geest S, Zullig LL, Dunbar-Jacob J, et al. ESPACOMP medication adherence reporting guideline (emerge). Ann Intern Med. 2018;169(1):30-35.

24. Leventhal H, Nerenz DR, Steele DJ, Taylor SE, Slinger JE. Illness representation and coping with health threats. In: Baum A, editor. Handbook of Psychology and Health. Hillsdale, NJ: Lawrence Erlbaum Associates; 1984:219-252.

25. Chaiken S, Wood W, Eagly A. Principles of persuasion. In: Higgins ET, Kruglanski AW, editors. Social Psychology. New York: Guildford Press; 1996:702-744.

26. Deci EL, Ryan RM. The support of autonomy and the control of behavior. In: Higgings ET, Kruglanski AW, editors. Social and Personality Perspectives. Philadelphia: Psychology Press; 2000:128-146.

27. Bandura A. Social Learning Theory. Englewood Cliffs, NJ: PrenticeHall; 1977: $247 \mathrm{p}$.

28. Hess LM, Raebel MA, Conner DA, Malone DC. Measurement of adherence in pharmacy administrative databases: a proposal for standard definitions and preferred measures. Ann Pharmacother. 2006;40(7-8):1280-1288.

29. Thompson K, Kulkarni J, Sergejew AA. Reliability and validity of a new medication adherence rating scale (MARs) for the psychoses. Schizophr Res. 2000;42(3):241-247.

30. Buurma H, Bouvy ML, de Smet PAGM, Floor-Schreudering A, Leufkens HGM, Egberts ACG. Prevalence and determinants of pharmacy Shopping behaviour. J Clin Pharm Ther. 2008;33(1):17-23.

31. Paes AHP, Bakker A, Soe-Agnie CJ. Impact of dosage frequency on patient compliance. Diabetes Care. 1997;20(10):1512-1517.

32. de Ridder D, Theunissen N. De rol van ziektepercepties in therapietrouw bij hypertensie [The role of illness perceptions in adherence to hypertension regimens]. Gedrag \& Gezondheid: Tijdschrift voor Psychologie en Gezondheid. 2003;31(4):237-249. Dutch. 
33. van Vugt M, de Wit M, Hendriks SH, Roelofsen Y, Bilo HJG, Snoek FJ. Web-based self-management with and without coaching for type 2 diabetes patients in primary care: design of a randomized controlled trial. BMC Endocr Disord. 2013;13(1):53.

34. van Vugt M, de Wit M, Bader S, Snoek FJ. Does low well-being modify the effects of PRISMA (Dutch DESMOND), a structured selfmanagement-education program for people with type 2 diabetes? Prim Care Diabetes. 2016;10(2):103-110.

35. Lam WY, Fresco P. Medication adherence measures: an overview. Biomed Res Int. 2015;2015(5 supplement):1-12.

36. Liu H, Golin CE, Miller LG, et al. A comparison study of multiple measures of adherence to HIV protease inhibitors. Ann Intern Med 2001;134(10):968-977.

37. Partridge AH, Avorn J, Wang PS, Winer EP. Adherence to therapy with oral antineoplastic agents. J Natl Cancer Inst. 2002;94(9):652-661.
38. Roter DL, Hall JA, Merisca R, Nordstrom B, Cretin D, Svarstad B. Effectiveness of interventions to improve patient compliance. Med Care. 1998;36(8):1138-1161.

39. van de Steeg N, Sielk M, Pentzek M, Bakx C, Altiner A. Drugadherence questionnaires not valid for patients taking blood-pressurelowering drugs in a primary health care setting. J Eval Clin Pract. 2009;15(3):468-472.

40. Velligan DI, Lam Y-WF, Glahn DC, et al. Defining and assessing adherence to oral antipsychotics: a review of the literature. Schizophr Bull. 2006;32(4):724-742.

41. Deakin TA, Cade JE, Williams R, Greenwood DC. Structured patient education: the diabetes X-PERT programme makes a difference. Diabet Med. 2006;23(9):944-954.

\section{Publish your work in this journal}

Patient Preference and Adherence is an international, peer-reviewed, open access journal that focuses on the growing importance of patient preference and adherence throughout the therapeutic continuum. Patient satisfaction, acceptability, quality of life, compliance, persistence and their role in developing new therapeutic modalities and compounds to optimize clinical outcomes for existing disease states are major areas of interest for the journal. This journal has been accepted for indexing on PubMed Central. The manuscript management system is completely online and includes a very quick and fair peer-review system, which is all easy to use. Visit http://www. dovepress.com/testimonials.php to read real quotes from published authors.

Submit your manuscript here: http://www.dovepress.com/patient-preference-and-adherence-journal 